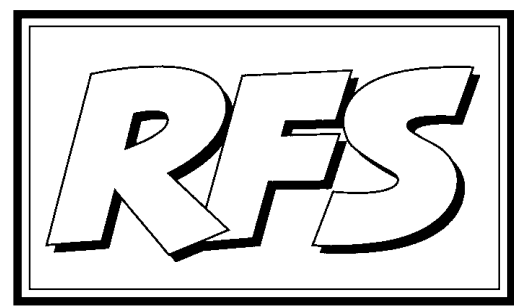

Revista de Fomento Social, 53 (1998), 177-202

\title{
La modernización:
}

\section{del etnocentrismo occidentalista}

a la globalización

Las descolonizaciones y el consiguiente surgimiento de un gran número de países independientes, que tuvieron lugar después de la segunda guerra mundial, propiciaron un considerable acrecentamiento del interés por la modernización, concebida como el proceso de cambio que requerían tales países para desarrollarse. En realidad, la preocupación por el cambio modernizador viene de muy atrás y está enraizada en la visión teleológica de la historia como progreso ilimitado que tanta fuerza tuvo en la evolución de la sociedad occidental y en el desarrollo del pensamiento sociológico clásico. A pesar de que está agotada la confianza en la idea de progreso y de que la sociedad urbano-industrial occidental (que fue la meta a alcanzar para la mayoría de los artífices y teóricos de la modernización) se halla inmersa en la crisis de la posmodernidad, en este trabajo se considera que todavía permanecen en pleno vigor las aspiraciones de democracia, desarrollo y bienestar social asociadas tradicionalmente a los procesos de modernización. Pero, como hoy está plenamente claro que ya 
no puede seguir manteniéndose la tradicional visión etnocéntrica occidentalista de tales procesos, se propone aquí un modelo para el análisis de los mismos en el presente contexto de globalización.

\section{Francisco ENTRENA DURÁN (*)}

\section{La modernización: un concepto impreciso y polisémico cuyas raíces vienen de muy atrás}

A partir de la segunda guerra mundial, las descolonizaciones y el acceso a la independencia de un gran número de las actuales nuevas naciones del llamado tercer mundo dieron lugar a que se desarrollaran las que se conocen como teorías de la modernización. Éstas pueden ser concebidas como herramientas para el estudio o el fomento de los procesos de cambio socioeconómico en que entraron tales naciones. En realidad, el término modernización está relacionado con la palabra moderno, cuyo uso viene de bastante atrás en la historia. En su versión latina, modernus, fue empleado a finales del siglo $\mathrm{V}$ para diferenciar del pasado romano y pagano el presente, que por entonces estaba paradigmatizado oficialmente por el cristianismo (Habermas: 1988, 87-88). Con unos contenidos que varían según el tiempo y las circunstancias en que es utilizada, la expresión moderno hace referencia una y otra vez a la forma en que es concebida una época, que es puesta en relación con la antigüedad pasada, con la finalidad de verse a sí misma como el resultado de un tránsito de lo viejo a lo nuevo.

Las gentes se consideraban a sí mismas modernas durante la época de Carlomagno, en el siglo XII, así como en la Francia de la última parte del siglo XVII, en el período de la conocida Querelle des Anciens et des Modernes. En definitiva, el vocablo moderno aparecía y reaparecía coincidiendo con aquellas etapas, en las que, en Europa, se generaba la conciencia de que se vivía una nueva era formada a través de una relación renovada con los antiguos, o, también, cuando se desarrollaba la conciencia generalizada de considerar a la antigüedad como un arquetipo susceptible de ser recuperado y, de alguna forma, imitado.

(*) Profesor del Departamento de Sociología de la Universidad de Granada. 
El hecho de que las raíces del término modernización vengan de muy atrás en la historia occidental es una de las principales razones de la variedad de significaciones que le son atribuidas y de su consiguiente ambigüedad. La especial imprecisión de dicho término hace que por él puedan entenderse muchas cosas. Así, con él puede hacerse referencia a la sustitución de los paradigmas mítico-religiosos de pensamiento y de acción por otros pretendidamente de carácter científico positivo, al establecimiento de fórmulas de legitimación de carácter legal-racional, en el sentido weberiano de estas palabras (García Cotarelo: 1985, 24). También, el concepto de modernización alude a la mejora de los cauces de comunicación y de información, al incremento de los niveles de participación ciudadana o a la generalización de la burocracia.

Carlota Solé, al hablar de las implicaciones ideológicas, de los reduccionismos y de las confusiones que se originan al definir el término modernización, efectúa las siguientes puntualizaciones:

$1^{\mathrm{a}}$. No es correcta la identificación de modernización con progreso, evolución, desarrollo (económico, político o social) y cambio social.

$2^{\text {a }}$. El concepto de modernización no puede ser reducido únicamente a los procesos de industrialización y de urbanización.

$3^{\mathrm{a}}$. Al equiparar, etnocéntricamente, el concepto de modernización con el de occidentalización (en el sentido más estricto, con los vocablos americanización o europeización), se tiende a restringir su aplicación y capacidad explicativa al ámbito de aquellas sociedades que adoptan el modelo de cambio social modernizador seguido por occidente (Solé: 1976, 27-35).

Si bien es cierto que el concepto de modernización no puede ser reducido a ninguno de los fenómenos mencionados en los tres puntos anteriores, en mayor o menor medida, todos esos fenómenos constituyen indicadores de que la sociedad concreta en la que se manifiestan se encuentra inserta en un proceso de modernización. Una manera de considerar este proceso en un sentido general y amplio es concebirlo como un cambio social que conlleva el paso de lo tradicional a lo moderno. En este sentido, muchos autores emplean el término modernización para hacer referencia al tránsito hacia la modernidad, expresión con la que caracterizan el período iniciado a partir de lo que en el contexto europeo occidental se denomina el Renacimiento. 
La modernidad y su visión teleológica de la historia como progreso ilimitado

Los ideales de la Ilustración francesa conllevaron que, en gran medida, dejara de tener efecto la fascinación ejercida por los clásicos del mundo grecolatino antiguo, que se había incrementado especialmente a partir del Renacimiento. Así, desde entonces (y, sobre todo, a lo largo del siglo XIX), la idea de ser moderno, más que un afán por volver la vista a la antigüedad de Grecia y de Roma, empezó a significar que se abogaba por la instauración de unos paradigmas económico-sociales, político-institucionales y simbólico-legitimadores distintos a los de la sociedad entonces vigente, considerada, sobre todo, a raíz de la Revolución francesa, como la encarnación del Antiguo Régimen. Ser moderno implicaba, también, que se era partícipe de una gran fe en las que se suponían enormes posibilidades de desarrollo de la razón científica moderna, así comoen el progreso ilimitado del conocimiento, de la sociedad y de la moralidad hacia cotas cada vez más altas. Se conformó de esta manera una nueva modalidad de concebir la conciencia moderna que, en vez de dirigir su mirada más o menos mixtificadora hacia los paradigmas del pasado, trataba de ubicar los referentes legitimadores de su praxis y de su discurso teórico en el futuro. En éste se situaba el horizonte utópico salvífico y liberador hacia el que se dirigía la historia humana, según la versión secularizada de la teleología judeocristiana generada por la modernidad. Así, frente a la visión naturalista y cíclica del curso del mundo dominante en la mentalidad antigua, uno de los principales rasgos característicos de la modernidad es que únicamente ella es «la que, desarrollando y elaborando en términos puramente terrenales y seculares la herencia judeocristiana (la idea de la historia como historia de la salvación articulada en creación, pecado, redención, espera del juicio final), confiere dimensión ontológica a la historia y da significado determinante a nuestra colocación en el curso de la historia» (Vattimo: 1986, 11).

En consonancia con esta visión teleológica de la historia, dejando de lado sus diferentes terminologías y específicas orientaciones ideológicas y epistemológicas, la idea sociológica decimonónica con respecto al progreso, así como las teleologías de Hegel y de Marx, son susceptibles de ser concebidas como sucesivas tentativas (y críticas de las mismas) encaminadas a conseguir en el futuro la realización de un orden humano armónico y justo (Entrena: 1989, 611). 
Tentativas que se esforzaban por lograr la materialización de un modelo utópico de sociedad futura. Así, tanto las teorías del progreso como la filosofía hegeliana, coincidieron en servirse de la promesa del porvenir como señuelo con el que legitimar el modelo de sociedad implícito en el, entonces en pleno proceso de afianzamiento, paradigma político-institucional del Estado burgués. A este respecto, en lo que se refiere a Hegel, su propósito de atribuir un sentido teleológico secularizado a la historia se concretó en una propuesta filosófica que legitimaba el orden sociopolítico específico del Estado burgués, concibiéndolo como un eslabón en la cadena de la que él consideraba que era la trayectoria universal de la historia de la humanidad en su tránsito hacia la idea abstracta del espíritu absoluto, que, a fin de cuentas, venía a ser el arquetipo hegeliano de la armonía, de la redención y de la reconciliación definitiva de la humanidad.

Por lo que respecta a la idea de progreso, a través de portavoces de ella insertos en el ámbito de la evolución del pensamiento sociológico, como por ejemplo Comte, propugnaba que el proceso de desarrollo y avance de la sociedad industrial conduciría, de modo inexorable, hacia niveles cada vez más altos de armonía, integración, bienestar y conocimiento.

A diferencia de los planteamientos que se acaban de esbozar, Marx se sirvió del paradigma utópico de la futura sociedad comunista (en la que, según él desaparecerían la opresión, la explotación del hombre por el hombre y toda forma de alienación humana, a la vez que se conseguiría la armonización entre el trabajo manual y el intelectual) como modelo de orden alternativo que contraponer al orden burgués, frente al que iba dirigida toda su ingente tarea revolucionaria y crítica. Tarea, por otra parte, encaminada a mostrar las limitaciones que imponía la sociedad y el Estado burgués a la realización de los ideales de progreso infinito a nivel intelectual, político y socio-económico.

«El fracaso de esta razón burguesa, o del Estado burgués, se pone de manifiesto a lo largo de los siglos XIX y XX en todos los aspectos deshumanizadores y alienantes de la sociedad capitalista y da pie a la economía política de Marx. La reivindicación hegeliana del Estado moderno, como manifestación más alta de la razón, es para Marx una formulación ideológica, una reconciliación entre el universal y el particular pensada pero no real. La razón ilustrada burguesa en su plasmación real estaba, por tanto, plagada de contradicciones y era portadora por 
igual de progreso y de destrucción. Sólo explicitando estas contradicciones y haciéndolas explotar se podría reconstruir la futura emancipación de la sociedad, y a esa tarea se apresta toda la tradición marxista» (Picó: 1988, 15).

La Revolución era el paso previo propuesto por Marx para materializar esa futura emancipación de la humanidad que él identificaba con la instauración de la sociedad comunista. Modelo de sociedad, mediante el que, de una u otra forma, se trataban de materializar unos ideales que, en definitiva, constituían la versión marxiana de las aspiraciones características de la conciencia moderna ilustrada. En este sentido, las revoluciones legitimadas en el marxismo y los regímenes de socialismo real establecidos a partir de ellas pueden ser, en cierto modo, considerados como tentativas de acceder a la materialización de los ideales de la modernidad ilustrada (es decir, de modernización) por unas vías distintas de las adoptadas por los sistemas de economía de mercado.

\section{La modernización en el contexto europeo occidental}

Replantearse lo que supuso, en el contex to europeo occidental, el proceso de tránsito de la sociedad tradicional del Antiguo Régimen a la moderna es un paso que puede resultar bastante esclarecedor. En este sentido, está en lo cierto Pascuino cuando se lamenta del desequilibrio existente entre el gran número de estudios efectuados sobre la modernización del tercer mundo y las escasas investigaciones realizadas acerca de este tema con respecto a los países desarrollados (Pascuino: 1984, 305 y ss.). Al efectuar estudios en torno a la modernización de la sociedad occidental, podemos darnos cuenta de que una serie de rasgos característicos de ella, que son propuestos habitualmente como requisitos a los que debe ajustarse todo proceso modernizador, son, en realidad, el resultado de la evolución histórica específica de esa sociedad y no el reflejo de unas condiciones supuestamente inherentes a la modernización en general. Es decir, se trata de evitar, al estudiar o tratar de llevar a cabo otros procesos de modernización, el traslado etnocéntrico de la trayectoria concreta y de los circunstanciales resultados históricos que han dado lugar a la modernidad occidental. Circunstanciales, ya que cabe, lógicamente, imaginar que, de haberse seguido otros caminos, tales resultados habrían sido diferentes. Y, lo que en 
occidente podría haber sido de otras maneras y por otros caminos, también puede suceder de formas distintas y por vías diferentes a las occidentales en otros contextos socio-culturales.

En el mundo europeo occidental, el proceso de paso de la sociedad estamental señorial del Antiguo Régimen a la sociedad moderna supuso una serie de cambios, en la estructura económico-productiva, en la organización políticoinstitucional y en los paradigmas simbólico-legitimadores, que constituyen el contex to histórico del nacimiento de la Sociología como ciencia. De hecho, tales cambios se fraguaron a lo largo de un dilatado proceso de grandes transformaciones que arranca prácticamente desde el Renacimiento. Proceso que logra sus primeros frutos significativos con la Ilustración, ya que puede afirmarse que en el espíritu humanista de ésta y en los ideales de libertad, igualdad y fraternidad de la Revolución francesa están ya claramente explicitados, teórica y prácticamente, los fundamentos del racionalismo humanista y antropocéntrico característico de la sociedad moderna. Las transformaciones que genera dicha sociedad se concretan en una serie de cambios que muy esquemáticamente se sintetizan aquí en el cuadro I.

A nivel teórico, la preocupación por el cambio modernizador es una constante a lo largo del desarrollo del pensamiento sociológico. La Sociología es la ciencia que trataba de analizar y explicar (y, frecuentemente, también aportar soluciones tendentes a propiciar la transformación de la realidad existente) los fenómenos de cambio social que acontecían en el entorno socio-histórico en el que se originó como ciencia. Su desarrollo estuvo, en gran parte, motivado por tales fenómenos, ocasionados como es sabido, por el surgimiento y desarrollo de la sociedad industrial moderna.

Dehecho, las distintas tipologías elaboradas por clásicos de la Sociología como Comte, Spencer, Marx, Tönnies, Durkheim o Weber constituyen, cada una de ellas desde su particular punto de vista y específico planteamiento teórico, una forma de dar cuenta de las transformaciones acaecidas en el contexto europeo occidental a lo largo de época en que se desarrollaron. Estas transformaciones amenazaban los presupuestos organizacionales, económico-productivos y legitimadores, sobre los que se había asentado el mundo hasta entonces, invalidando certezas y creando problemas que incitaban a la reflexión y/o a la acción a los primeros sociólogos; de tal forma que, cada uno de ellos a su manera y desde su peculiar perspectiva ideológica y teórica, trataba de explicar, prever, controlar 


\section{CUADRO I}

\section{Contraste entre la sociedad del Antiguo Régimen y la Moderna}

\begin{tabular}{|c|c|}
\hline SOCIEDAD DEL ANTIGUO RÉGIMEN & SOCIEDAD MODERNA \\
\hline $\begin{array}{l}\text { QLASESSOCIALES: no existen en el sentido } \\
\text { modernodel término, hayestamentos; es decir, } \\
\text { grupos sociales, cadauno con una situación } \\
\text { jurídicay unos privilegios específicos. }\end{array}$ & $\begin{array}{l}\text { CASESSOCIALES: E principio de igualdad } \\
\text { antelaley detodos losindividuosimplicaque } \\
\text { entrelos distintos grupos sociales no existan } \\
\text { diferenciasdeordenjurídicocomoenlasocie } \\
\text { dad estamental. Tales diferencias, que sólo } \\
\text { persisten en el plano social y económico, } \\
\text { determinanlaexistenciadeclases sociales. }\end{array}$ \\
\hline $\begin{array}{l}\text { ESTRUCTURAECONÓMICOPRODUCTVA:Pre } \\
\text { dominantementeagraria. }\end{array}$ & $\begin{array}{l}\text { ESTRUCTURAECONÓMICOPRODUCTVA:Bá } \\
\text { sicamenteindustrial y deservicios. }\end{array}$ \\
\hline $\begin{array}{l}\text { SISTEMADEPROPIEDAD: En régimen patri- } \\
\text { monial. }\end{array}$ & $\begin{array}{l}\text { SISTEMA DE PROPIEDAD: Privada de tipo } \\
\text { capitalista. }\end{array}$ \\
\hline $\begin{array}{l}\text { ORGANIZACÓNINSTITUAONAL:Predominan- } \\
\text { tementeseñorial-feudal. Enel senodel Estado } \\
\text { coexisten distintos señoríos y comunidades } \\
\text { locales, cada uno con una normativa legal } \\
\text { específica; es decir, el Estado alberga una } \\
\text { pluralidaddejurisdicciones. Eparentescoylas } \\
\text { relaciones decarácter personalistafundamen- } \\
\text { tanlaorganizacióninstitucional deestasocie- } \\
\text { dad, en laquepreponderael status adscrito. }\end{array}$ & $\begin{array}{l}\text { ORGANIZACGÓNINSTITUCIONAL: Constituida } \\
\text { por lo que se denomina el Estado Moderno, } \\
\text { caracterizado por uncentralismoadministrati- } \\
\text { voyunidadjurisdiccional entodo el territorio. } \\
\text { Laformalidad burocráticay unacomplejaes- } \\
\text { tructuraprofesional fundamentanlaorganiza- } \\
\text { ción institucional de esta sociedad, en laque } \\
\text { preponderael status adquirido. }\end{array}$ \\
\hline $\begin{array}{l}\text { MARCOSDELEGITIMACIÓN: Deunacentua- } \\
\text { do carácter religioso. La preponderanciadel } \\
\text { pensamiento mágico o religioso tienden a } \\
\text { suplir las carencias técnicas en lo relativo ala } \\
\text { manipulacióninstrumental del medio. }\end{array}$ & $\begin{array}{l}\text { MAROOSDELEGTIMACGÓN:Amparadosnor- } \\
\text { malmenteenel establecimiento deunaCons- } \\
\text { titución política y en principios como el de } \\
\text { soberaníapopular, libertad, igualdad, etc. Prin- } \\
\text { cipios legitimadosdeacuerdo conlosplantea } \\
\text { mientos dela Razón, lacual también sirvede } \\
\text { soportejustificativoalasinstituciones, modos } \\
\text { depensar ydeactuar delasociedad moderna } \\
\text { Sociedad con preponderanciadelacienciay } \\
\text { altavaloracióndelainstrucción pública, en la } \\
\text { que la racionalización general de la vida va } \\
\text { acompañadadeunaseparaciónentrelosacro } \\
\text { yloprofanoydeunnluralismoreligiosoymoral. }\end{array}$ \\
\hline
\end{tabular}


o acelerar el cambio conducente a la modernidad.

La crítica funcionalista al evolucionismo clásico supuso un decaimiento del interés por el cambio, que no volvió a ser un asunto prioritario para la Sociología hasta que, pasada la segunda guerra mundial, a partir de los años cincuenta del siglo XX, se desarrollaron las teorías de la modernización. En este sentido, conviene precisar que, si bien la modernización es una forma de cambio social, esto no quiere decir que puedan equipararse los conceptos de modernización y de cambio social. Con referencia a esta cuestión se ha escrito lo siguiente:

«Numerosos sociólogos consideran modernización como el proceso de cambio social contemporáneo, desde una perspectiva histórica. Sin embargo, desde la perspectiva histórica en que se define tan frecuentemente la noción de cambio social, todo cambio social puede llamarse modernización como contrapuesto a una situación anterior, tradicional. En consecuencia, modernización sería, como cambio social, un concepto de por sí tan amplio, que al pretender abarcar cualquier tipo de cambio que una sociedad pueda experimentar en cualquiera de sus esferas (económica, política, cultural, etc.), resultaría excesivamente vago y por lo tanto inoperativo. Laidea de modernización, entendida como un tipo de cambio social desde una perspectiva neo-evolucionista e histórica, sería, en efecto, un cajón de sastre.

Tal vez la diferencia más notable entre ambos conceptos estribe en que modernización contiene la idea implícita de superioridad, mientras que cambio social no posee necesariamente tal connotación (Solé: 1984, 14-15).

Según Robert Nisbet, el cambio es «una sucesión de diferencias en el tiempo en unaidentidad persistente» $(1975,294)$. Pues bien, si aceptamos esta definición de cambio, entonces la idea de modernización, como un tipo de cambio que es, queda incluso despojada de esa superioridad que se le ha solido atribuir desde las perspectivas valorativas tendentes a identificarla con un etnocéntricamente idealizado paradigma urbano-industrial occidental. Algunas de tales perspectivas serán examinadas a continuación. 


\section{La modernización como occidentalización: algunas de las principales aportaciones teóricas}

A) David E. Apter (1970, 282 y ss.) considera que el proceso de modernización crea problemas de coordinación y de control social de tal envergadura que los sistemas políticos democráticos no resultan fácilmente viables. Además, las posibilidades de viabilidad de tales sistemas parecen tender a decrecer a medida que se acerca su transición a la industrialización. Sin embargo, a diferencia de lo que acontece en las sociedades que se encuentran en proceso de modernización, las sociedades industrializadas avanzadas, de acuerdo con su continua necesidad de recurrir a múltiples fuentes de información, tienen una tendencia sistémica a adoptar alguna modalidad de democracia. Todo ello porque, a juicio de Apter, existe al parecer una relación inversa entre coerción e información. Relación que, aunque este autor reconoce que está sin confirmar, él fundamenta en la suposición de que, a medida que avanza la modernización, la complejidad del proceso da lugar a la creación de la necesidad de más y más autoridad jerárquica para controlarla. Las consecuencias que se desprenden de ello son formuladas por el propio Apter en las proposiciones siguientes:

$1^{\mathrm{a}}$. Al incrementarse el grado de jerarquía se estrecha el círculo de los que toman las decisiones y se agranda la gama de elites representacionales que quedan excluidas de esta posibilidad.

$2^{\mathrm{a}}$. Cuanto mayor es el nivel de jerarquía, más concentrado se encuentra el poder de los que toman las decisiones.

$3^{\mathrm{a}}$. Los que toman las decisiones, con el fin de conservar su poder, pueden recurrir a la coerción o a la recompensa.

$4^{\mathrm{a}}$. Al ser eliminadas las elites representacionales en potencia se incrementa la competencia por el poder entre los que quedan para tomar decisiones, a la vez que se acrecienta la necesidad de habilidades manipulativas por parte de los que poseen el liderazgo central.

$5^{\text {a }}$. Cuanto mayor es la pérdida de información, mayor es la necesidad de recurrir a una fuerza coercitiva reguladora, por ejemplo, de carácter militar o policial.

$6^{a}$. Cuanto mayor es la confianza depositada en la coerción, más significativa se hace la función del ejército o de la policía, y mayor es la necesidad de someterlos a control. 
En resumen:

«1. Aumento de la jerarquía - menor responsabilidad.

2. Menor responsabilidad - mayor coerción.

3. Mayor coerción - menor información.

4. Menor información - mayor coerción.

5. Mayor coerción - aumento de la jerarquía»

(Apter: 1970, 308).

Por contra, en las sociedades industriales, crece la necesidad de información, y la coerción se torna cada vez más disfuncional con respecto al sistema. De este modo, en tales sociedades existe esa tendencia sistémica a la democracia a la que se aludía antes.

Una de las críticas que pueden hacérsele a la aportación de Apter es que resulta demasiado abstracta, vaga e imprecisa como para poder ser adecuada para la explicación de casos concretos en su totalidad. De hecho, el autor recurre a ejemplos tan heterogéneos, descontextualizados y diversos como los países de América Latina, Rusia, China, Guinea o Mali para fundamentar su teoría.

B) S. N. Eisenstadt destaca el papel que determinadas elites sociales pueden tener en la modernización. En su opinión, puede «ser útil distinguir, por una parte, aquellas elites sociales que -como muchas de las de Europa occidental entre las dos guerras mundiales, y asimismo muchas de las elites contemporáneas en los nuevos estados-, aún creando nuevos símbolos y estructuras políticas, no lograron efectuar ninguna transformación estructural que facilitara un desarrollo continuado en sus respectivas sociedades; y, por otra parte, las elites de México, de Rusia, de Turquía, de Japón, de Israel, y las primeras elites modernizantes de Europa occidental, que fueron relativamente más afortunadas -si bien en formas muy diferentes-en la realización de tales cambios y transformaciones» (Eisenstadt: 1970, 17).

En lo que se refiere a lograr la modernización, las razones del éxito de este segundo tipo de elites son explicadas por Eisenstadt basándose en que ellas «tendieron a una mayor cohesión, y al mismo tiempo trataron de efectuar una transformación de los valores internos de los grupos y estratos más amplios. Se propusieron forjar en las esferas ideológica y axiológica un conjunto de nuevos 
símbolos que dieran significado a los procesos de cambio. Se esforzaron en crear un conjunto flexible de símbolos y una identidad colectiva que, sin negar las tradiciones existentes, la incorporara a las nuevas estructuras simbólicas» (1970, 17).

Sin dejar de considerar el papel que ciertas elites puedan efectivamente desempeñar en los procesos de modernización, lo que resulta chocante es ¿cómo puede Eisenstadt agrupar en un mismo bloque a realidades tan dispares como las de Japón, Turquía o México como ejemplos que corroboran su teoría?

C) Daniel Lerner habla de la necesidad de que se produzca una empatía de las sociedades en proceso de modernización con las ya modernizadas. La empatía es el mecanismo psíquico que posibilita que una persona se ponga en la situación de otra, identificándose con una función, un período de tiempo o un lugar distinto del suyo. Los medios de comunicación de masas, altamente desarrollados en el mundo actual, actúan como difusores de la empatía, pues, mediante ellos, se acelera «la educación de la movilidad psíquica que capacita a las personas para imaginarse en situaciones diferentes a la suya» (Lerner: 1975, 173).

El enfoque de Lerner es más elaborado y sofisticado que el de los que propugnan una especie de «transferencia de instituciones» de las sociedades más modernizadas a las menos modernizadas. Dicha transferencia raramente acontece en la realidad, y cuando tiene lugar, como por ejemplo en aquellos casos en que las sociedades en proceso de modernización han adoptado las instituciones electorales amparadas en el sufragio universal propias de las sociedades modernizadas, los efectos resultantes han sido no solamente intrusivos y perturbadores, sino además, con frecuencia, decididamente disfuncionales en lo que se refiere a propiciar la modernización de la sociedad. La lección que Lerner extrae de este fracaso de la pretensión de transferir instituciones es la de que la modernización ha de ser sistémica para lograr resultados eficaces y duraderos. Modernización que, en consecuencia, ha de «imponer a los miembros de la sociedad en cuestión una transformación múltiple y profunda de su comportamiento, que permita una nueva y coherente forma de vida» $(1975,174)$. Una nueva forma de vida, cuyos comportamientos y aspiraciones resulten de una auténtica adaptación (es decir, empaticen realmente) con los paradigmas de las sociedades modernizadas incorporados por las socieda- 
des que aspiran a modernizarse. Ello, porque las instituciones del mundo moderno no pueden ser simplemente transferidas, sino que han de ser transformadas. De modo análogo, los «modos de vida no pueden ser adoptados, sino adaptados» (Lerner: 1975, 174).

La capacidad de adaptación, que es la característica más sobresaliente de las sociedades auténticamente modernizadas, es lo que les permite desarrollarse más rápidamente que las sociedades en transición. A pesar de las ayudas (en la mayoría de los casos pueden ser conceptuadas como limosnas) que las sociedades desarrolladas aportan a las denominadas por Lerner sociedades en transición, el autor considera que éstas no lograrán modernizarse hasta que no desarrollen una capacidad para acelerar y mantener su propio crecimiento. Para ello, es preciso que las sociedades en proceso de modernización difundan ampliamente entre sus componentes los modos de vida y las instituciones de la movilidad, la empatía y la participación. «La movilidad es el mecanismo inicial; la gente debe estar bien dispuesta y preparada y ser capaz de apartarse de donde está y de lo que es» $(1975,174)$.

En definitiva, Lerner resalta una exigencia fundamental en todo proceso de modernización: la necesidad de una especie de resocialización de los recursos humanos implicados en él de acuerdo con unos nuevos valores y pautas de comportamiento vital.

\section{Ideología y crítica de la modernización}

Con toda probabilidad, tanto para los países que pretenden acceder a ella como para la generalidad de los organismos o personas que bienintencionadamente tratan de hacerla posible mediante su acción práctica o intelectual, la búsqueda de la modernización constituye la expresión de un afán de propiciar la salida del atraso y del subdesarrollo para determinadas sociedades. Un afán de conseguir la equiparación con aquellos países que simbolizan la culminación del progreso, del bienestar económico-social y de la estabilidad política ¿Cómo se explican entonces los efectos negativos que frecuentemente ha tenido la modernización? La toma en consideración de la ideología que subyace a los planteamientos modernizadores, así como de las críticas que éstos han suscitado, puede aportar alguna luz a la cuestión que se acaba de formular.

Refiriéndose a la modernización rural, Dolors Comas d'Argemir y Jesús 
Contreras hacen la siguiente observación crítica:

Las transformaciones que tienen lugar, a raíz de la modernización, «no son vistas como procesos dialécticos de interacción y ajuste entre instituciones y grupos sociales de dentro y de fuera de un pueblo o comunidad, sino como un proceso mecánico en el que el pueblo cambia como resultado de un conjunto de fenómenos impuestos desde fuera y que vienen a desestructurar el orden social secular» $(1990,15)$.

Si en el texto anterior se sustituyen las palabras pueblo o comunidad por las de país o sociedad, resulta entonces que la crítica que en el mismo se hace es perfectamente aplicable a muchos de los planteamientos de los teóricos de la modernización. Éstos, más que tomar en cuenta la dialéctica que se establece, en cada caso específico de modernización, entre las influencias exógenas y las condiciones endógenas de cada sociedad o país, tienden, como se ha visto, a limitarse a establecer las dificultades a superar y los requisitos que deben cumplirse para que las sociedades no modernizadas acaben incorporando los esquemas político-económicos y los modos de vida(Lerner), de las sociedades occidentales modernas. Sociedades, que son concebidas acríticamente, desde los presupuestos ideológicos y los aprioris, más o menos desarrollistas y etnocéntricos, presentes, usualmente, en las teorías de la modernización. Se trata del etnocentrismo expansivo de la sociedad occidental que recurre ahora a la estratagema de la modernización, de la misma forma que en épocas pretéritas se sirviera, sucesivamente, de los pretextos de la evangelización y de la civilización para legitimar sus propósitos de conquista, y para que ésta no se redujera sólo al plano político, económico o social, sino que también trascendiera a la dominación cultural y espiritual de los pueblos conquistados.

Como reacción frente a la modernización, se desarrollaron una serie de perspectivas teóricas críticas con respecto a ella, entre las que sobresalen las aportaciones de S. Amin (1974) y G. Frank (1970). Éstas se sustentan en postulados como el del intercambio desigual, el de la teoría de la dependencia, o el de la subordinación de las economías de determinados países subdesarrollados a las de los industriales modernizados. La crítica formulada por estas aportaciones se basaba, sobre todo, en enfatizar el carácter desigualitario de la dialéctica relacional que se establece entre los países o sociedades modernizados 
y los subdesarrollados. Dentro de esta perspectiva teórica se desarrollaron en el ámbito latinoamericano, durante los años sesenta, los trabajos de Fernando H. Cardoso y de Enzo Faletto (1969). Los teóricos de la dependencia resaltan los efectos internos que, en lo relativo a obstaculizar el desarrollo de las sociedades latinoamericanas, han supuesto las profundas asimetrías económicas, políticas y culturales existentes entre ellas y las sociedades del mundo desarrollado.

Una aportación más elaborada dentro de estas perspectivas críticas es la de Immanuel Wallerstein, quien plantea la existencia de un sistema económico mundial, en el que existe una estructura internacional de división del trabajo que tiende a traspasar las fronteras políticas y culturales. Para ilustrar la división geográfica del trabajo en el sistema mundial capitalista Wallerstein elaboró los conceptos de el centro, entendido como espacio desde donde se explota y domina al resto del sistema; la periferia, en la que se incluyen aquellas zonas suministradoras de materias primas al centro y que por lo tanto son explotadas por éste; y, la semiperiferia, que constituye una categoría residual en la que se integran una serie de regiones ubicadas entre las explotadoras y las explotadas (Wallerstein: 1984,489).

\section{La vigencia de la idea de la modernización en un mundo inserto en la crisis de la posmodernidad y de la globalización}

Pese a las anteriores críticas, resulta todavía pertinente hablar de modernización, dado que aún hoy, pasada la euforia desarrollista de décadas anteriores, es evidente la existencia de procesos de profundas transformaciones estructurales, a todos los niveles, que están teniendo lugar en determinadas sociedades. Es un hecho la tendencia de estas sociedades a ir incorporando, gradualmente, las pautas de las que consideran modernizadas. Tendencia que, independientemente de que se produzca de manera inducida desde los países más desarrollados o como resultado de las necesidades de adaptación a la lógica económica, social y política dominante a escala mundial, constituye también una manifestación de que aún permanecen vivos los ideales de mejora social que desde sus inicios suscitara la modernidad.

«La modernidad ... es un modo de civilización característico, que se opone a la tradición, es decir a todas las otras culturas anteriores o tradicionales: 
frente a la diversidad geográfica y simbólica de éstas, la modernidad se impone como una homogeneidad, irradiada mundialmente a partir de occidente ... que connota globalmente toda una evolución histórica y un cambio de mentalidad» (Baudrillard: 1979, 139).

Sin duda, la gran capacidad de influjo y de seducción de la modernidad está estrechamente vinculada con la exacerbada confianza en un futuro de prosperidad, armonía y bienestar social para la civilización urbano-industrial occidental que impregnó y determinó el desarrollo de aquella idea antropocéntrica de progreso ilimitado que tanta extensión alcanzó durante el siglo XIX. Más tarde, los distintos enfoques teóricos y procesos de modernización socioeconómica producidos a partir de la segunda guerra mundial siguieron siendo alentados y legitimados por unas aspiraciones muy similares a las de dicha idea de progreso. De acuerdo con este antropocentrismo, los sujetos humanos son protagonistas y dueños absolutos de su entorno sociohistórico, así como de su medioambiente natural, concebido como una realidad a su servicio, externa a ellos y dispuesta para ser regulada, controlada y sometida completamente a sus exigencias. Se trataba de un planteamiento desarrollista que se sustentaba en una engañosa «metáfora del crecimiento» que presuponía la analogía entre el cambio en la sociedad y los procesos de crecimiento de un organismo individual (Nisbet: 1969, 166).

Sin embargo, hoy está en crisis de legitimidad la concepción del desarrollo como crecimiento y se tiende a optar por fórmulas de desarrollo sostenible que, partiendo de la constatación de que el medio ambiente no es indestructible ni sus recursos inagotables, propugnan una extensificación productiva encaminada a garantizar la conservación de dicho medio. Crisis de legitimidad porque el hecho es que todavía sigue prevaleciendo una manera de producir y de organizar la producción que, no sólo amenaza el equilibrio natural y medioambiental, sino también el social por los altos niveles de desempleo y de exclusión social que estructuralmente genera. La noción de sociedad del riesgo, acuñada con notable éxito por Ulrich Beck (1993), resulta muy adecuada para conceptualizar esta imprevisible situación que ha sido tipificada por Giddens (1996, 13 y 85) como de incertidumbre fabricada, ya que, en gran medida, es el resultado de la propia acción socio-productiva humana.

En estas circunstancias, es obvio que ya no está en vigor el ideal antropocén- 
trico occidentalista de progreso en que se sustentaba la modernización. Por eso, ¿sigue teniendo sentido hablar de modernización? Dicho de otro modo, ¿se puede mantener aún viva la confianza en la capacidad emancipadora atribuida al proceso histórico de tránsito hacia la sociedad moderna occidental? La respuesta es no, pues, como señala Josep Picó, la noción substantiva de racionalidad y la idea del hombre sobre la cual se ha basado la tradición occidental han llegado a ser el blanco de una crítica fundamental» $(1988,36)$. A raíz de dicha crítica, ha perdido vigencia dicha sociedad, que, en palabras de Daniel Bell contemplaba «la historia como un progresivo avance del poder del hombre sobre la naturaleza y sobre sí mismo» $(1977,23)$.

En el lugar de la modernidad, y como consecuencia de la propia evolución de la tradición de ruptura y de crítica de ella, se instaura progresivamente la llamada posmodernidad, en la que se ha experimentado la pérdida del sentido de la continuidad histórica (Lipovetsky: 1990, 51). Se trata de una sociedad que vive en el presente, en la que «se disuelven la confianza y la fe en el futuro, ya nadie cree en el porvenir de la Revolución y el progreso, la gente desea vivir el 'aquí' y 'ahora', buscando la calidad de vida, y la cultura personalizada. La atención por lo social se vuelve hacia el individuo y se difunde el narcisismo individual y corporativo. El individuo sólo tiene ojos para sí mismo o para su grupo» (Picó: 1988, 37). Se experimenta, de este modo, una tendencia hacia la reemergencia creciente de movimientos sociales y formas de vinculación social, en las que preponderan relaciones de naturaleza grupal, lo que, sin duda, está relacionado con la agudización de la crisis de credibilidad de muchas de las grandes organizaciones e instituciones (Entrena: 1998).

En definitiva, con el término posmodernidad se alude a la realidad de un mundo en el que se ha hecho patente una situación de crisis y de incertidumbre generalizada. Un mundo en el que se ha producido el fin de la vigencia de una visión unilineal y ascendente de la historia, con la consiguiente pérdida de la confianza optimista en el progreso ilimitado que impregnaba la conciencia de bastantes pensadores decimonónicos. La sociedad posmoderna ha conllevado, también, lo que McLuhan diera en denominar el paso de la galaxia de Gutemberg a la aldea global electrónica, a la vez que el agotamiento de las potencialidades utópico-subversivas que en otros tiempos conllevara la idea de la Revolución. Como acertadamente precisa Gianni Vattimo, «lo posmoderno se caracteriza no sólo como novedad respecto de lo moderno, sino también como disolución de la 
categoría de lo nuevo, como experiencia del 'fin de la historia', en lugar de presentarse como un estadio diferente (más avanzado o más retrasado; no importa) de la historia» $(1986,12)$. Fin de la historia como proyecto de progreso y de superación continua, tal y como la entendía la modernidad ilustrada.

Hoy más que de modernización tiende a hablarse de globalización. En realidad, la modernización era ya un proceso de globalización de la sociedad moderna occidental, una paulatina generalización al resto del mundo de sus pautas productivas, organizacionales y simbólico-legitimadoras. Pero, en la presente era de incertidumbre posmoderna están en crisis de legitimidad tales pautas. Lo que hoy se entiende por globalización, más que un proceso de occidentalización del mundo, hace referencia a una situación en la que se ha producido una especial intensificación y aceleración de los flujos de información y socio-económicos a través de todo el planeta que se traduce en una constante elevación del ritmo de circulación de personas, ideas y mercancías en todas las direcciones del globo terráqueo ¿Qué sentido tiene hablar de modernización, entendida básicamente como proceso de acercamiento a y/o de implantación de los paradigmas de la modernidad occidental, en una sociedad planetarizada en la que parecen agotadas las posibilidades vaticinadas otrora por los artífices y portavoces de esa modernidad?

La respuesta a esta cuestión es que merece la pena seguir reflexionando sobre la modernización porque la idea de la misma continua siendo, para muchos, un síntoma o un acicate de cambio y de desarrollo social. Para éstos, modernizarse implica todavía avance, desarrollo, superación de una determinada situación socio-histórica, democratización, bienestar; en suma, mejora social. Así, a pesar de la crisis de la modernidad, persisten en pleno vigor las aspiraciones asociadas tradicionalmente a los procesos de modernización. Lo único que sucede es que hoy está completamente claro que ya no puede seguir manteniéndose el tradicional planteamiento etnocéntrico occidentalista de tales procesos. Una prueba de ello es el fracaso y las contradicciones que, con frecuencia, ha conllevado el intento de materialización de la idea de que, para modernizarse, bastaba algo así como con la aplicación mimética y acrítica de los paradigmas occidentales, lo que, a su vez, es una de las principales motivaciones de que, en nuestros días, la modernización constituya un referente de rechazo para determinados colectivos sociales. Este es el caso, por tomar ejemplos que nos conciernen especialmente dada su relativa proximidad con nuestro entorno, de 
Irán o Argelia. Países, en los que el recurso a la legitimación fundamentalista islámica refleja una pretensión de repliegue colectivo en una cierta mixtificación / exacerbación de los valores religioso-culturales tradicionales, que se corresponde con un repudio de lo moderno, identificado con lo occidental.

Frente al planteamiento de la modernización como occidentalización, en el presente trabajo se propone un modelo para el análisis de la misma que procura tomar en cuenta el hecho de que, en la actualidad, cada vez es más patente que existen diversas manifestaciones de la modernidad y caminos hacia ella. Esto, porque, si bien es cierto que la globalización implica una creciente homogeneización a escala planetaria (1), también es verdad que, como reacción frente a ella, está teniendo lugar una gradual reemergencia o reafirmación de identidades y pautas locales o regionales de desarrollo y de organización social. De ahí, que pueda hablarse hoy de múltiples modernidades en una era de globalización (2).

\section{A modo de conclusión: un modelo de análisis de la modernización en el contexto de la globalización}

Para estudiar la modernización, en vez de partir de unas condiciones generales previas de lo que se entiende por ella, que siempre pueden ser contradichas por los procesos específicos mediante los que tiene lugar, resulta más clarificador y eficaz analíticamente tratar de examinar la evolución sociohistórica de cada caso concreto desde una perspectiva globalizante. Sin embargo, la necesidad de centrarse en las especificidades de cada caso particular no obsta para que se procure lograr una unificación de los criterios de análisis, que, de hecho, es posible y recomendable. Precisamente, con esta finalidad se propone aquí la elaboración y el empleo de un modelo analítico totalizador, en el que se consideran las transformaciones que acarrea el paso de una sociedad tradicional a otra moderna (es decir, la modernización) en sus respectivas dimensiones

(1) Como dice Robertson (1992, 396), la globalización conlleva un «conjunto de procesos que conducen a un mundo único». Esto origina que la totalidad de las gentes del mundo se encuentren insertas en una sola sociedad global (Albrow: 1990, 9).

(2) Me estoy sirviendo aquí del, a mi juicio muy acertado, título del 34 Congreso Internacional convocado por el Instituto Internacional de Sociología de la Universidad de Tel-Aviv (Israel) para los días 11 al 15 de Julio de 1999. 
económico-social, político-institucional y simbólico-legitimadora. Dimensiones de lo tradicional y de lo moderno que son consideradas como variables que evolucionan de forma autónoma pero interrelacionada, al mismo tiempo que se considera necesario tomar en cuenta la dialéctica del proceso que se establece en el tránsito de la versión tradicional a la moderna de ellas.

Además del sesgo etnocéntrico occidentalista que los caracterizaba, todos los enfoques antes referidos de la teoría de la modernización eran, en mayor o menor grado, reduccionistas y simplificadores, pues ni siquiera intentaban tomar en consideración un número suficientemente amplio e ilustrativo de la diversidad de variables que intervienen en cualquier proceso de modernización. Por contra, el modelo que se propone a continuación es lo bastante omnicomprensivo y apto como para poder ser aplicado al examen de distintos casos de modernización, a la vez que las tres dimensiones que contempla procuran dar cuenta de las más fundamentales de entre las diversas variables intervinientes en cualquier proceso modernizador. Asimismo, el modelo en cuestión es muy idóneo para estudiar íntegramente los cambios de la estructura social, concebida a nivel macro-social, que conllevan la generalidad de los procesos de modernización. Lo más significativo que ha de considerarse en cada una de las tres dimensiones de dicho modelo se puede resumir de la forma que sigue:

A) Dimensión económico-social. Han de incluirse en ella las transformaciones conducentes al desarrollo tanto a nivel económico como social, a la vez que los cambios en las relaciones de producción, en la estructura ocupacional y de clases, en la división del trabajo, etc.. En las presentes circunstancias de globalización, estas transformaciones no pueden hacerse sin una adecuada inserción en un mercado que se desenvuelve en un escenario mundial. Asimismo, en contraste con la tradicional presuposición de los teóricos de la modernización de que ésta implicaba crecimiento económico, hoy la meta ha de ser la búsqueda de fórmulas de desarrollo sostenible y respetuosas con el mantenimiento del equilibrio social y natural. En un contexto, en el que tiene lugar una creciente extensión de las grandes corporaciones transnacionales, la búsqueda del desarrollo ha de centrarse prioritariamente en tratar de encontrar la maneras más ventajosas posibles de inserción de las economías locales en la dinámica socioeconómica global de la que, inevitablemente, forman parte.

B) Dimensión político-institucional. Dentro de ella se consideran, básica- 
mente, las transformaciones dirigidas a propiciar una especie de normalización de la violencia. Se trata de una tendencia a la institucionalización de la misma y de las formas de ejercicio del poder o de la autoridad (Huntington: 1972), así como de los conflictos sociales, mediante el establecimiento de cauces dentro del sistema para la generación, reivindicación y satisfacción de las demandas colectivas. En el presente contexto, en el que la creciente preponderancia de organismos e instituciones supranacionales amenaza o disminuye el margen de soberanía del Estado-nación, uno de los retos es conseguir que éste se inserte en lo global y, al mismo tiempo, conserve una relativamente efectiva capacidad de actuación.

C) Dimensión simbólico-legitimadora. Se incluyen en ella las transformaciones, inherentes a todo proceso de modernización, en los valores y en los símbolos culturales que legitiman (explican y/o justifican) el orden social. En lo que respecta al ámbito del Estado-nación, cabe considerar aquí las modificaciones y subsiguientes crisis en los símbolos y en los valores (así como en los factores y agentes que los sustentan) que conlleva la formación de una identidad colectiva a nivel de tal ámbito. Con referencia a esta cuestión, hay que resaltar «que tener experiencias históricas comunes, una prolongada continuidad territorial y la posesión de una lengua común parecen ser los factores que condicionan la solución positiva de la crisis de identidad y de legitimación» (Pascuino: 1984, 62). En cualquier caso, el reto está en lograr el equilibrio entre el particularismo nacional y la ineludible necesidad de insertarse en un marco de legitimidad de referencia universal. Sólo consiguiendo este equilibrio se estará en condiciones de evitar la propensión defensiva al cierre a lo de fuera (relativamente frecuente en estos tiempos de incertidumbre y de globalización), al imposible aislamiento, y se propiciará que la identidad nacional constituya una de las mejores garantías de la autoconfianza y capacidad del colectivo poblacional que integra un Estado-nación específico para esa incardinación ventajosa en lo global a la que se hacía referencia antes.

Las cuestiones a tener en cuenta, señaladas en cada una de la tres dimensiones anteriores, adquieren unos contenidos específicos en cada uno de los particulares procesos de modernización que pueden ser objeto de estudio. En suma, como ya se ha dicho antes, cabe hablar de múltiples modernidades en la 
era de la globalización.

Aparte de las ya referidas, otras ventajas del modelo que acabo de proponer, para el análisis de la modernización, son:

- No parte del establecimiento de unas condiciones apriori (generalmente han sido las que se dan en el contex to moderno occidental) como requisitos que, ineludiblemente, debe cumplir todo proceso de modernización. A este respecto, Guillermo O’Donnell señala que tanto «la concepción de la modernización como un proceso tendente a reproducir básicamente las sociedades ya 'desarrolladas', como la idea de que ese proceso transcurriría en etapas que implican sucesivas aproximaciones a aquella meta, tienen como premisa fundamental que el conjunto de factores causales operantes en el mundo ‘subdesarrollado' no es sustancialmente diferente del que tuvo lugar en las sociedades que esta concepción considera como ya modernizadas» (1976, 245). El etnocentrismo occidentalista, presente en tales concepciones de la modernización, trata de ser evitado en este modelo no anteponiendo unas condiciones previas (ni occidentalizantes ni de ningún otro tipo) como requisitos a los que, necesariamente, la misma ha de ajustarse.

- Frente al ahistoricismo, usualmente presente en muchas de las teorías acerca de la modernización, en las que se presentan las características de ésta como algo universal y descontextualizado, con este modelo se pretende centrar la atención en la naturaleza histórica y el carácter específico de todo proceso modernizador.

- Por último, al no identificarse en este trabajo el paradigma de la modernización con ningún sistema económico-político-social concreto (generalmente, las teorías de la modernización tenían in mente el sistema capitalista), el modelo de análisis que aquí se propone trata de ser válido para explicar los procesos modernizadores, tanto del contexto capitalista como del de los países del socialismo real, que, al fin y al cabo, también son susceptibles de ser considerados como la expresión de un intento de llevar a cabo la modernización por unas vías distintas a la economía privada rechazada por el marxismo.

«Para ver claro hay que partir de una distinción sencilla, pero fundamental, entre los tipos de sociedad y las formas de modernización ... (según que 
la misma) está dirigida por grupos económicos privados o por el Estado hay que hablar de capitalismo o de socialismo. Esas palabras no designan, pues, tipos de sociedad, sino formas sociales de modernización» (Touraine: 1992,11$)$.

Para una mejor comprensión de los procesos concretos de modernización acaecidos dentro de la órbita del socialismo real hay que tomar en cuenta que tales procesos no son la expresión de un desarrollo endógeno, derivado de la propia dinámica interna de la sociedad, sino la manifestación de una forma de modernización exógenamente propiciada, ante la crisis o la debilidad de las fuerzas sociales autóctonas para llevarla a cabo. A este respecto, la tradicional oposición entre capitalismo y socialismo es, entre otros aspectos, una manifestación de dos formas respectivas de desarrollo: la endógena y la exógena. El capitalismo corresponde a una modalidad de desarrollo endógeno porque la clase dirigente (concepto que hace referencia a la estructura social) es a la vez la elite que dirige el desarrollo al controlar el Estado. El desarrollo es endógeno cuando se dan las condiciones económico-sociales, político-institucionales y culturales adecuadas para ello. Por contra, el desarrollo ha sido exógenamente propiciado en los casos en que la sociedad presentaba serios obstáculos a la modernización. En aquellas situaciones en las que el desarrollo es endógeno, los movimientos sociales y la sociedad civil son fuertes; pero, allí donde aquel es exógeno, los agentes sociales son débiles y, con frecuencia, están subordinados a los poderes políticos.

En muchos países, la sociedad civil y sus agentes sociales eran fuertes, pero habían entrado en un estado de crisis, habitualmente después de una guerra exterior o a raíz de un proceso de inestabilidad interna de carácter revolucionario, desencadenado «por la descomposición de una sociedad todavía en gran parte tradicional. En éstas situaciones, el Estado modernizador no sólo ha tenido que reemplazar a la sociedad, ha debido hablar en su nombre, devorándola, y ese lenguaje ventrílocuo se ha convertido en el del totalitarismo, tanto fascista como comunista» (Touraine: 1992, 11).

La característica debilidad de la sociedad civil en los países subdesarrollados es una de las principales razones del papel de supremacía, generalmente, desempeñado por el Estado en los procesos modernizadores de tales países. Esta debilidad era también evidente en la Rusia zarista de 1917 y de ahí que la forma 
de modernización acometida por el aparato estatal soviético (y propugnada para los países que se vieron forzados a formar parte de su área de influencia en el marco del guerra fría) fuera exógenamente propiciada, ante la debilidad de los movimientos sociales internos rusos de entonces (Touraine). Con esta estrategia se acabó, paradójicamente, impidiendo la posibilidad de una posterior emergencia de tales movimientos organizados y, consiguientemente, no se hizo posible que se pudiera proceder a una institucionalización de los conflictos y de las formas de ejercicio del poder y de la autoridad (Huntington). Ante esta situación, se comprenden mejor la actual crisis de las sociedades y el proceso de desintegración de los Estados del ámbito de los regímenes del socialismo real, desencadenados a raíz del derrumbamiento de tales regímenes, al mismo tiempo que resulta más explicable la relativa facilidad con la que los mismos fueron desmantelados, una vez que se debilitó la rígida estructura burocrático-militar, básicamente autoritaria, que los sustentaba, como consecuencia de la política aperturista de Mijail Gorbachov. 


\section{Bibliografía}

Albrow, M. (1990), «Introduction» to Albrow, Martin; and King, Elizabeth, Globalization, Knowledge and Society, Sage Publications and ISA, London.

Amin, S. (1974), El desarrollo desigual, Ed. Fontanella, Barcelona.

Apter, D. E. (1970), Estudio de la modernización, Amorrortu, Buenos Aires. BAudrillard, J. (1979), Voz «modernité» en Enciclopaedia Universalis, volumen 11, France, S.A., París.

BECK, U. (1993), «De la sociedad industrial a la sociedad del riesgo. Cuestiones de supervivencia, estructura social e ilustración ecológica», Revista de Occidente, $\mathrm{N}^{\mathrm{o}} 150$, noviembre.

Bell, D. (1977), Las contradicciones culturales del capitalismo, Alianza Universidad, Madrid.

Cardoso, F. H. y Faletto, E. (1969), Dependencia y desarrollo en América Latina, Siglo XXI, México.

Comas D'Argemir, D. y Contreras, J. (1990), «El proceso de cambio social», Agricultura y Sociedad, abril-junio n ${ }^{\circ} 55$.

EISENSTADT, S. N. (1970), Ensayos sobre el cambio social y la modernización, Ed. Tecnos, Madrid.

Entrena Durán, F. (1989), «Sobre la crisis de la modernidad», Religión y Cultura, $\mathrm{n}^{\circ} 171$.

ENTRENA, F. (1998), «From the credibility crisis of formal organizations to the reemergence of the group: an ecosystemic approach», Free Inquiry in Creative Sociology, Volume 26, Number 1, Oklahoma State University, USA.

Frank, A. G. (1970), Capitalismo y subdesarrollo en América Latina, Editorial Signos, Buenos Aires.

García Cotarelo, R. (1985), Los partidos políticos, Editorial Sistema, Madrid. GidDEns, A. (1996), Más allá de la izquierda y la derecha. El Futuro de las políticas radicales, Ediciones Cátedra, Madrid.

Habermas, J. (1988), «Modernidad versus posmodernidad», en Modernidad y posmodernidad, selección de textos compilados por Josep Picó, Alianza Editorial, Madrid.

Huntington, S. P. (1972), El orden político en las sociedades en cambio, 
Paidós, Buenos Aires.

LERNER, D. (1975), «Modernización: aspectos sociales», en Enciclopedia Internacional de las Ciencias Sociales, Ed. Aguilar, Madrid.

Lipovetsky, G. (1990), La era del vacío. Ensayos sobre el individualismo contemporáneo, Anagrama, Barcelona.

Nisbet, R. (1969), Social Change and History, Oxford University Press, Nueva York.

Nisbet, R. (1975), Introducción a la Sociología. El vínculo social, Ed. Vicens-Vives, Barcelona.

O’Donnell, G. (1976), voz «Modernización» en Diccionario de Ciencias Sociales, Instituto de Estudios Políticos, Madrid, 1976, Tomo II.

Pascuino, G. (1984), Modernización y desarrollo político, Ed. Hogar del Libro, Barcelona.

Picó, J. (1988), Modernidad y posmodernidad, Alianza Editorial, Madrid.

Robertson, R. (1993), Globalization. Social Theory and Global Culture, SAGE Publications, London.

SolÉ, C. (1976), Modernización: un análisis sociológico, Editorial Península, Barcelona.

SolÉ, C. (1984), Prólogo a la edición española de la obra de Gianfranco Pascuino (1984) Modernización y desarrollo político, Hogar del Libro, Barcelona. Touraine, A. (1992), «Capitalismo y socialismo», en Diario «El País», de fecha 4-3-92.

VAtтimo, G. (1986), El fin de la modernidad, Nihilismo y hermenéutica en la cultura posmoderna, Gedisa, Barcelona.

W ALLERSTEIN, I. (1984), El moderno sistema mundial. La agricultura capitalista y los orígenes de la economía-mundo europea en el Siglo XVI (Vol. I), Ed Siglo XXI, Madrid. 